\title{
TRADITIONAL VS AGILE PROJECT MANAGEMENT IN THE SERVICE SECTOR
}

\author{
Bojan Grebić \\ Serbian Armed Forces, The Ministry of Defence of Republic Serbia
}

\begin{abstract}
The paper focuses on the comparison of traditional and agile project management methods with the aim of examining the possibility of applying agile methodologies in the service sector, notwithstanding the fact that they are most used in projects in the IT sector. Based on the fundamental characteristics of the traditional PMI, IPMA and PRINCE2 methodologies, as well as on the specifics of the agile approach, a comparative analysis of theoretical aspects of traditional and agile methodologies is made, with the emphasis on Scrum, thus a comparison is made between applications of both types of methodologies on examples of projects in the service sector. The result of the comparative analysis is the final assessment of the possibility of applying agile methods in projects in the service sector, which serves to determine the elements of traditional methodologies which can be improved by the use of agile methodologies.
\end{abstract}

Key words: traditional methodologies, agile methodologies, Scrum, comparative analysis, service sector

\section{THE SERVICE SECTOR}

The service sector began rapidly developing at the turn of the $20^{\text {th }}$ century and today it is an essentially important factor in every country's economy, often contributing the most to GDP. A country's economy depends to a large extent on the service sector functioning regularly and continually encouraging production, as well as further growth and development. Precisely because of this, the importance of project management in the service sector becomes greater day by day.

The execution of projects in the service sector is largely determined by the characteristics of services as an economic phenomenon, and in the foreground are (Kotler, \& Keller, 2006): intangibility, variability, heterogeneity, inseparability of production from consumption, user participation in the service process and the lack of ownership of services. Essentially, services cannot be detected by senses, their consumption cannot be delayed nor can they be stored, ownership of services cannot be acquired, and the participation of the user is mandatory in the process of providing service. Relying upon these service characteristics, project mangers make plans, decisions and assessments, and complete other project tasks.

\section{TRADITIONAL PROJECT MANAGEMENT METHODS}

Great military campaigns or, for example, the construction of the Egyptian pyramids, were projects in some ways because they required dedication of a significant number of people, maintaining discipline and control, as well as determining the necessary workforce or number of soldiers, expenses, time and, also, predicting enemy tactics. Since there are similarities between original and contemporary projects, one can come to a conclusion that the project management is a result of the accumulation of knowledge and skills that ensued from experience in organizing and completing complex tasks.

The foundations of project management as a field of study were established by Henry Gantt, the creator of the Gantt chart, but its rapid development began later, in the 1950s, when the PERT method was developed, followed by CPM, WBS and other techniques which have significantly facilitated the execution of projects. Nowadays, project execution also requires a new kind of 
organization and usage of information technology (Jovanović, 2012).

\subsection{The PMI Methodology}

The Project Management Institute was founded in 1969 in Philadelphia, Pennsylvania. All the knowledge, skills and techniques required for successful project management were listed by the PMI in its publication A Guide to Project Management Body of Knowledge, or simply the PMBOK Guide. According to the PMBOK Guide, project management consists of 10 knowledge areas (PMI, 2017a): integration, scope, schedule, cost, quality, resource, communications, risk, procurement and stakeholder management.

\subsection{The IPMA Methodology}

International Project Management Association, known also as IPMA, was established in 1965 in Switzerland. IPMA project management standards are found in the handbook The IPMA Individual Competence Baseline (IPMA ICB $\left.{ }^{\circledR}\right)$ which is designed for all the individuals working in project, program or portfolio management fields and not exclusively for Project Managers. The competence of those participating in a project consists of 28 elements divided into 3 areas - Perspective, People \& Practice. The first area pertains to the capability of comprehending the project in a broader context, the second area includes people and interpersonal skills, while the third area is related to the application of technical knowledge and project management skills.

\subsection{PRINCE2 Methodology}

PRINCE (Projects In Controlled Environments) methodology was developed by the British government in 1989 and it was initially designed for the IT sector. It was upgraded to PRINCE2 in 1996 and today, PRINCE2 is a common methodology for managing projects which has a broad application irrespective of the type or complexity of the project. PRINCE2 methodology describes the practical knowledge required throughout the execution of a project (themes), general rules which 56 should be followed over the course of the project (principles), as well as the processes constituting project execution (Axelos Group, 2017).

\section{THE AGILE APPROACH}

Business entities which utilize changes in the best way possible are characterized by agility - the ability to make changes and respond to changes with the aim of making profit in a turbulent business environment (Highsmith, 2009). Centering on flexibility as opposed following a plan in its entirety today is one of the key elements of doing business successfully which has led to the development of agile project management methods.

The term Agile is defined by certain authors as a set of methodologies which are used for project management in the IT sector. However, that definition is too narrow, since Agile is also a global framework for action, way of thinking and style of business management and decision-making based on agile values and principles which are commonly known as the agile approach. The agile approach enables one to respond to changes quickly and efficiently and adapt to new conditions, because it focuses only on making initial plans, while most of the actual planning is done during the execution of the project.

\subsection{Agile Values}

In 2001, seventeen IT experts signed The Agile Manifesto in order to change the current way of developing computer software. The Agile Manifesto defines basic values and principles which help individuals and organizations interpret the agile approach in the best way possible and realize the benefits of its application. Compared to the traditional approach to project management, the agile approach values (Agile Alliance, 2001):

- Individuals and interactions over processes and tools;

- Working software over comprehensive documentation;

- Customer collaboration over contract negotiation;

- Responding to change over following a plan. 


\subsection{Agile Principles}

The Agile Manifesto defines 12 principles which are the lodestar in agile project management, and their implementation within an organization is requisite on the way to achieving project agility. The application of agile principles consists of early and continual value creation, accepting requests for changes even in the later phase of a project, delivering working software frequently, focusing on simplicity, technical excellence and good design, but also on building self-organizing teams, establishing direct communication and on the constant increase in efficiency (Agile Alliance, 2001).

\subsection{Scrum Basics}

The main problem with traditional methodologies is their linear nature which prevents adaptability during unforeseen situations. The solution to this problem was found in Scrum - a framework within which people can address complex issues while delivering products of the highest quality in a productive and creative manner (Schwaber, \& Sutherland, 2017). Defining Scrum as a framework, its creators highlighted the possibility to fit numerous techniques and methodologies within this concept.

Scrum introduces three completely new roles in projects which did not exist in that form beforehand, and those are: Product Owner, the individual responsible for maximizing values in a project and protecting stakeholders' interests, most often those of external customers (Voice of the Customer VOC); Scrum Master, the individual responsible for all the participants in a project adequately comprehending Scrum and the agile approach (the administrator of the Scrum framework); Development Team, a group of professionals which work on developing products and which possess the required knowledge and directly create value in a project (Schwaber, \& Sutherland, 2017; Scrum Study, 2017).

Scrum methodology also prescribes the following mandatory events: Sprint, a period lasting a month or less which results in a complete, usable and potentially shippable product increment (Mersino, 2015;
Schwaber, \& Sutherland, 2017); Sprint Planning, defining tasks, priorities and ways of their execution; Daily Scrum, a fifteenminute meeting of the team members at the beginning of every workday, focused on current planning and resolving problems; Sprint Review, a meeting during which all the tasks completed over the course of Sprint are revised and stakeholders get to see the progress of the project; Sprint Retrospective, an internal meeting of the team members centered on improving action after Sprint.

The main source of information and the base for measuring progress are Scrum Artifacts: Product Backlog, a prioritized list of project requirements and product characteristics which is constantly updated in concordance with what goes on in a project (individual responsible: the Product Owner); Sprint Backlog, a sum of selected Product Backlog items and the plan for delivering product increment and reaching the Sprint goal (Schmidt, 2009), those responsible: the Development Team; Product Increment, which is delivered by the Development Team at the end of each Sprint, including the values created during the previous Sprints, individual responsible for giving approval being: Product Owner (Schwaber, \& Sutherland, 2017).

\section{THE COMPARATIVE ANALYSIS OF TRADITIONAL AND AGILE METHODS' APPLICATION IN THE SERVICE SECTOR}

Adaptability is the key element which separates the traditional and agile approaches to project management. The traditional approach is tailored to stable systems in which the majority of processes are known beforehand, which is why the end results are also predictable. On the other hand, the agile approach is designed for systems which exist in conditions of great uncertainty and frequent change in the environment and, because of that, all project participants are required to be flexible. The projects' success will depend upon exactly that ability to adapt and implement changes in the project efficiently. 


\subsection{General Differences}

The lower level of flexibility present in the traditional approach to project management is reflected by planning and documenting a project at its very beginning, that is, at the moment when the project products are least known and which is principally meant for generating ideas, thus, there is a risk of missing opportunities and responding inadequately to changes.

The agile approach eliminates this risk by limiting planning to a briefer time period, focusing on the most important activities that ensue. Taking into consideration the specific characteristics of services, above all the continual customer participation, projects in the service sector should definitely avoid early documentation accumulation.

Traditional methodologies accurately define techniques and tools for managing different segments of the project, which is certainly a virtue, but agile organization gives the team the freedom to independently choose methods and techniques which shall be used for the execution of the project. However, those methods and techniques are often defined within the frame of some traditional methodologies but the opportunity to choose and adapt gives them a completely new form in an agile environment.

Traditional methodologies are even more present in the service sector, since organizations and individuals are well acquainted with their elements, but that does not mean that there is no place for agile methodologies in this sector. On the contrary, even though the agile approach is still in the area of the new and the unknown which is why its implementation is often delayed, specific characteristics of services and of the agile approach are complementary and their combination can accelerate processes and increase project efficiency.

The significance of agile methodologies has been acknowledged by the most important project organizations, so, as a response, PMI, IPMA and PRINCE2 handbooks for agile project management were published.

\subsection{Project Scope Management and Project Integration Management}

Traditional methodologies place planning before the beginning of a project, which significantly increases the risk of not fulfilling the stakeholders' requirements. A Project Manager is entirely responsible for planning - this individual selects the tasks which shall be executed, determines interdependencies and makes a schedule, causing team members to be discontented with the schedule, deadlines and workload.

On the other hand, agile methodologies eschew planning out a project in its entirety before the beginning of its execution and focus on a limited time period which is predicable enough (Sprint). Scrum entails formation of the Product Backlog by the Product Owner, whereby the Development Team independently selects items which shall be worked on during Sprint. Thus, Development Team members actively participate in planning, coordinate their own capacities with the tasks they need to complete and continually create values while working on most important tasks. The planning process is repeated separately for each Sprint, which enables efficient implementation of changes in a project.

Example. Applying the traditional approach in a project organizing a marketing campaign would entail defining specific goals and planning the execution of all tasks before the campaign, but if the competition took countermeasures, the market conditions changed, or a new channel of communication were found, it is uncertain whether the traditional approach would lead to expected results. However, by applying the Scrum, the whole team participates in adapting plans and revising the Sprint goal, which enables the process of creating values to continue smoothly.

\subsection{Project Schedule Management}

Traditional methodologies tend to fix the time of the execution of certain tasks or of the whole project, while Scrum does not demand the scope of the project to be constant, which is why it focuses on a planning period which must be fixed. The duration of Sprint is not 
changed, which enables the team members to fit the workload into the time frame and according to the capacity of the team instead of the traditional matching of the team capacity and time at disposal to the tasks which need to be executed. Now what is put first is executing tasks of the highest priority, which is why products are delivered to end users much earlier. The traditional approach has a great disadvantage in this segment, because it does not differentiate between important and unimportant requests, so it fulfils them all according to the phase of the project, which is why value is created much later.

Regarding Gantt charts, they can be used alongside agile methodologies, especially in organizations which are in transition from the traditional to the agile approach, i.e. in projects which have characteristics of both approaches, where they would serve to demonstrate time necessary for checking items off the Sprint Backlog, as well as for fitting them within the Sprint time frame.

Example. In the domain of schedule management, traditional methodologies in a project introducing new accounting software in an accounting firm would manifest through planning the project at its beginning, which prevents accurate prediction of the time it would take to deal with bugs or optimize software performance, while, with the agile approach to planning, these problems would simply be transferred to the next Sprint or they would be given a higher rank, so they would be resolved accordingly.

\subsection{Project Cost Management}

The traditional approach puts business related to budget under the supervision of a company's management, project office, Project Manager, or some other project institution depending on the significance and the place the project and project organization have within the company. Scrum determines the role of a Product Owner who manages expenses along with a Development Team, approves expenses and provides necessary resources. In most cases, resources are not collected in their entirety before the project, as is the case with the traditional approach. Rather, capital is partially allocated which means that the project is financed according to its progress and delivered product increments.

A change in stakeholders' requests and product characteristics usually lead to additional expenses if the traditional approach is adopted precisely because expenses are predicted much before they are incurred. The agile approach allows the Development Team to coordinate its activities with the budget by choosing tasks the execution of which incurs expenses which correspond to available resources. Such treatment of expenses eliminates unnecessary spending and focuses on tasks which contribute the most to the value creation process.

An important characteristic of the agile approach is the possibility of making profit before a project's final completion. Since each Sprint results in shipping functional project increments which have market potential, it is clear that agile projects generate profits much earlier compared to traditional projects.

Example. Executing a project focusing on service adaptation of a business center using traditional methodologies would require estimating costs for executing tasks before the work has even begun. However, problems can arise if there is a need to complete tasks beyond the defined scope or if the team does not have the capacity for them. In these situations, agile methodologies demonstrate greater efficiency, since obstacles do not have to be removed at the moment they appear and the execution of problematic tasks is delayed until the conditions for their successful completion are created.

\subsection{Project Organization and Communication Management}

In the traditional approach, a project team is the most common type of project management organization, with the emphasis on the leading role of the Project Manager in the process of achieving desirable results. Team members do not have a formal role in decision-making, except when the Project Manager delegates some authority to them. In that way, a significant number of 
responsibilities is concentrated in the role of the Project Manager, who is often burdened with various tasks.

Agile methodologies do not acknowledge the Project Manager's role and shift the focus onto the team which is directly involved in delivering products. Teams independently decide upon their approach and the activities which shall be performed, but only in the domain of achieving defined goals, thus the team members are collectively responsible for a project's success or failure. In essence, most of the responsibilities of the traditional Project Manager have been delegated to the Development Team (e.g. planning and operational decision-making).

The roles of Product Owner and Scrum Master do not completely replace a Project Manager, but the tasks usually completed by this individual are divided between them. Namely, the Product Owner guides team members, but also protects the stakeholders' interests, being different from the Project Manager, who only cooperates with them. The Scrum Master performs the role of a motivator, educator and communicator, but is never involved in the decision-making process concerned with creating products. Additionally, Scrum Master removes obstacles which team members are faced with and protects their interests within an organization.

Direct communication and organizing meetings with a goal, team members' role and meeting schedules all defined in advance, are Scrum's great advantage when compared to traditional methodologies, since all the team members are completely involved and the stakeholders are enabled to participate, being continually informed of the project's progress. Traditional methodologies do not deal with the subject matter of a meeting in such detail and so meeting are most frequently held according to the ad hoc principle - problems have already arose and their resolvement is difficult and requires additional resources.

However, the flaw of agile methodologies is that they are not scalable enough for big projects which require several Development
Teams, and thus a larger number of Product Owners and Scrum Masters.

Example. Establishing the role of a Project Manager in a project organizing a music festival would facilitate managing a large number of people involved in the project, but this also has a flaw in the form of being them being less prepared for situations like lack of resources, poor location, etc. Agile methodologies would in this case would face the problem of coordinating activities of all team members, but it would also be easier to adapt to unexpected circumstances, like the performer cancelling the show.

\subsection{Project Risk Management and Change Management}

A Risk management plan in traditional methodologies is a separate document which is continually updated by Project Manager who is responsible for risk identification and response planning, along with the project team members. On the other hand, agile methodologies have an integrated risk management system in its structure. Scrum treats identified threats as Product Backlog elements and the Development Team selects those which they shall remove during Sprint, which enables generating a response at the moment when the occurrence of a threat is more evident, and the team is better prepared to deal with consequences.

Traditional methodologies have the tendency to increase the levels of risk following the project's progress, while agile methodologies are instantly focused on delivering usable products which prevents losses incurred due belated realization that the project is not justified. Their flaw is also a limited budget which requires additional resources or setting aside a contingency reserve, while agile teams fit those costs within the scope of available resources.

The traditional approach generally responds negatively to change, as it often results in editing the project plan or requiring additional resources. The agile approach welcomes change and views it as a positive factor, since it engenders product quality enhancement and better performance. 
Example. In a project starting a foreign language school, there is a risk of another school being in the same locations and in these conditions, the traditional approach would face the problem concerning procuring additional resources for promotion, while the agile approach would focus on using available resources irrespective of their initial purpose, because at that time decreasing the competitors' influence becomes the task of the highest priority. Furthermore, if there is a need to organize the first course earlier, the agile approach would have the advantage of allotting resources for the equipment of one classroom first and then for other activities.

\subsection{Project Quality Management}

Quality management in traditional methodologies is a separate functional area centered on developing products which meet acceptance criteria defined in project plans. Scrum in its structure has an integrated quality management system which entails delivering functional project increments at the end of each Sprint. Increments must be usable, which directly depends on the active implementation of acceptance criteria. Thus, the Development Team plans each day, assesses and improves project quality and do that alongside their regular activities.

Acceptance testing is often one of the last phases of a project in traditional methodologies. Problems arise if there is a need for changing product characteristics, because at that point it is difficult to make adjustments and it requires significant resources. Scrum does not allow this situation to occur, because product assessment is an integral part of each Scrum. Moreover, Scrum defines the Sprint Review meeting which is designated for assessing delivered increments and determining what changes need to be implemented so that products could meet acceptance criteria.

Example. Taking the traditional approach in a project developing new CRM software in a marketing supply chain would result in executing the project in phases so as to meet acceptance criteria defined at the project's initiation and the main product testing would be done after the development. The agile approach would gradually implement acceptance criteria during Sprints, quality check would be done alongside product development.

\subsection{Project Procurement Management}

Traditional methodologies appoint the organization working on the project and the Project Manager to be responsible for procurement and they strive to be within budget, which is why procurements are planned at the beginning of the project. This can lead to resource accumulation and money being tied to supplies, since resource amount and delivery time are often estimated according to initial plans when the level of project comprehension is significantly low, and the level of uncertainty quite high.

Scrum defines the responsibility of the Product Owner regarding procurements and the Development Team, besides identifying required resources, has more authority over determining specifics, suppliers and delivery time. Also, agile methodologies avoid contract negotiations and strive for dynamic cooperation with suppliers which enables procuring resources only in necessary amounts and delivery exactly at the time when resources are needed, but it also facilitates changing the supplier. Nevertheless, the agile approach is flawed in the sense that limited resources, like certain experts, are not always on the market, so their employment must be stipulated much earlier.

Example. If the traditional approach is applied in a project in adapting and opening a restaurant, material, equipment and furniture delivery, as well as employing workforce, would be stipulated at the beginning of the project, for all its phases. As regards Scrum, materials would be supplied before the adaptation, equipment shipping time would be agreed upon at the end of renovations and furniture would be delivered after all other work on the restaurant was finished. However, the aforementioned flaw of Scrum could manifest in the form of it being impossible to find a good chef.

\subsection{Project Stakeholder Management}

The traditional project team organization tends to show stakeholders in a bad light and 
the main reason for that is insufficient communication between project team members and stakeholders. Information exchange is done via the Project Manager who presents stakeholders' requests to the team members and if they change frequently, this leads to adverse project environment due to misunderstandings between both sides.

Scrum improves communication between stakeholders and the Development Team, since during the Sprint Review meeting, stakeholders state their expectations and get acquainted with the project's progress and team members are provided with direct guidelines for resuming operation, which helps avoid misunderstandings and discontent due to the change of initially defined stakeholders' requests. This interactive approach is based on direct communication and eliminates the disadvantages of the traditional methodologies, which ensue from the relationship with stakeholders being too formal.

Accordingly, agile methodologies attach greater importance to continual cooperation compared to traditional signing of a contract which defines in advance all criteria which products must meet. Traditional methodologies, although proactive, definitely are not interactive in stakeholder management.

Example. Using the traditional approach in a project introducing a new type of loan into a bank's portfolio, we would identify the bank's management as one of the stakeholders whom the Project Manager would occasionally inform about the progress, involve in the project and consult before making decisions. Nonetheless, the bank manager can decide to change the target group, loan structure, or to the decrease the resources for execution, which would negatively impact the team's further operations. Scrum would identify these request changes much earlier and implement them without significantly endangering project efficiency precisely because continuity in communication between the stakeholders and the Development Team working on delivering project's products.

\section{CONCLUSION}

Adopting agile principles and values results in shortening the planning period, fostering cooperation with the stakeholders and decreasing adversity towards change. Decreasing the number of responsibilities and the Project Manager's role in planning and controlling engenders atmosphere of trust in team members who would have more authority. Also, holding meetings regularly improves communication, among team members and likewise with stakeholders, too. Enhancement is also possible in the form of fitting time within the context of delivering increments, by editing milestones so they would include acceptance criteria, which would subordinate schedule to the value creation process, and group project activities and according to their priority. Additionally, this would lead to improvement in the domain of cost because of avoiding unnecessary expenses and increasing chances for making profit early.

Further traditional methodology improvement would entail the Project Manager and the team focusing on defining risk responses only for current project phases or for those which immediately follow, which would significantly increase efficiency in risk management and simultaneously coordinating the measures taken with the available budget. Accordingly, project plans must be fluctuating instead of the customary practice of fixing them to time and expense limitations which prevent regular change implementation.

As regards quality management, the Project Manager should integrate planning, providing and controlling activities into project phases in order to achieve formal existence of a quality management process over the course of the whole project and, thus, increase the possibility meeting acceptance criteria and fulfilling stakeholders' requests. Taking into consideration specifics of services and agile approaches' application in projects in the service sector, it is necessary to determine the optimal combination of traditional and agile methodologies which will enable projects to reach set goals. Choosing a proper combination which entails all the characteristics of projects in the 
service sector is not an easy task and it requires excellent knowledge of both agile and traditional approaches.

Summa summarum, successful application of agile methodologies in projects within the service depends most on the nature of the projects and project activities, project managers' preferences and specifics of the organization which carries out the project.

\section{REFERENCES}

Agile Alliance (2001). The Agile Manifesto, Corryton, USA: Author.

Axelos Group (2017). Managing Successful Projects with Prince $2-6^{\text {th }}$ Edition, London: Author.

Cooke, J. (2012). Everything You Wanted to Know About Agile, Cambridge: IT Governance Publishing.

Highsmith, J. (2009). Agile Project Management, Boston: Pearson Education Inc.

IPMA (2015a). Individual Competence Baseline in Agile World, Zurich, Switzerland: Author.
IPMA (2015b). Individual Competence Baseline for Project Management, Zurich, Switzerland: Author.

Jovanović, P. (2012). Upravljanje projektom, Beograd: Visoka škola za projektni menadžment.

Kotler, P., \& Keller, K. (2006). Marketing menadžment, Beograd: Data Status.

Mersino, A. (2015). Agile Project Management: A Nuts and Bolts Guide to Success, London: Vitality.

PMI (2017a). A Guide to the Project Management Body of Knowledge, PMBOK Guide - Sixth Edition, Newtown Square, USA: Author.

PMI (2017b). Agile Practice Guide, Newtown Square, USA: Author.

Schmidt, T. (2009). Strategic Project Management Made Simple, New Jersey: John Wiley\&Sons, Inc.

Schwaber, K., \& Sutherland, J. (2017). The Scrum Guide, Los Angeles: Creative Commons.

Scrum Study (2017). A Guide to Scrum Body of Knowledge $-3^{\text {rd }}$ Edition, Avondale, USA: Author. 